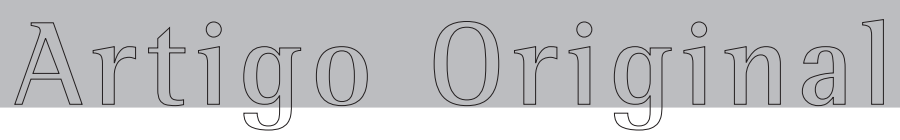

\title{
Punção aspirativa transbrônquica por agulha no diagnóstico e estadiamento do câncer de pulmão
}

Transbronchial needle aspiration in the diagnosis and staging of lung cancer

\author{
MAURO ZAMBONI (TE SBPT), DEBORAH CORDEIRO LANNES, \\ ANDREIA SALARINI MONTEIRO(TE SBPT), MARILENE S. NASCIMENTO, EDSON TOSCANO (TE SBCT), \\ AURELIANO MOTA DE SOUSA CAVALCANTI (TE SBCT), SAMUEL Z. DE BIASI CORDEIRO(TE SBCT), \\ PAULO DE BIASI CORDEIRO(TE SBCT)
}

Introdução: Nos últimos anos, a punção aspirativa transbrônquica por agulha vem sendo utilizada cada vez com maior freqüência no diagnóstico e estadiamento do câncer de pulmão, principalmente nos EUA. Entretanto, muito pouco se tem publicado a respeito do método em nosso país.

Objetivo: Avaliar a efetividade da punção aspirativa transbrônquica por agulha no diagnóstico e estadiamento do câncer de pulmão.

Método: Setenta e quatro punções aspirativas transbrônquicas por agulha, realizadas no Hospital do Câncer-INCA/MS, foram revistas retrospectivamente. Todos os pacientes realizaram tomografia computadorizada do tórax previamente ao procedimento.

Resultados: Onze (15\%) pacientes tinham massas mediastinais e $63(85 \%)$ massas hilares. Foram encontradas 76 alterações endoscópicas: alargamento da carina principal em 44 (59\%) pacientes, alargamento de carina secundária em 12 (16\%), compressão paratraqueal em 5 (7\%), compressão da parede posterior da traquéia em $3(4 \%)$, e compressão de brônquio principal em $5(7 \%)$ pacientes. 0 material foi satisfatório para o diagnóstico em 42 (57\%) pacientes e em 34 (46\%) o diagnóstico foi confirmado. 0 diagnóstico de doença maligna foi confirmado em 30/34 (88\%) pacientes: carcinoma indiferenciado de pequenas células em 10/30 (33\%), carcinoma escamoso em 7/30 (23\%), adenocarcinoma em 7/30 (23\%), e carcinoma não pequenas células em 6/30 (20\%) pacientes. Em 4/30 (12\%) pacientes foram diagnosticadas patologias benignas: tuberculose em $2 / 4(50 \%)$ e sarcoidose em $2 / 4(50 \%)$ pacientes. Não observamos nenhuma complicação com o método.

Conclusão: Nossa experiência em 74 pacientes mostrou que o procedimento é seguro, rápido em sua realização, com mínimas complicações e de utilidade no diagnóstico e estadiamento de pacientes com neoplasia pulmonar.

\section{J Bras Pneumol 2004; 30(2) 109-114}

Descritores: Broncoscopia/métodos. Carcinoma broncogênico/diagnóstico. Aspiração/métodos. Aspiração/ métodos.
Background: Transbronchial needle aspiration (TBNA) with a flexible bronchoscope has been used for many years in the United States of America to diagnose bronchogenic carcinoma. However little information on the subject is available in Brazil.

Objective: Assess the effectiveness of transbronchial needle aspiration for diagnosis and staging of lung cancer.

Method: A retrospective review was made of 74 TBNA performed at the National Cancer lnstitute, in Rio de Janeiro, Brazil. a thoracic computerized tomography had oreviouslbeen made of all patients. Eleven (15\%) patients exhibited mediastinal masses and 63 (85\%) hilar masses. Seventy six endoscopic alterations were detected: enlargement of the main carina in $44(59 \%)$ patients; enlargement of the secondary carina in $12(16 \%)$; paratracheal compression in $5(7 \%)$; posterior tracheal wall compression in $3(4 \%)$; main bronchus compression in 5 (7\%) AND BRONCHOSCOPY was normal in $5(7 \%)$ patients.

Results: Specimens were satisfactory for diagnosis in 42 (57\%) patients and in $34(46 \%)$ diagnosis was confirmed. Malignancy was confirmed in 30 of 34 patients (88\%): as follows: small cell undifferentiated carcinoma in 10 of 30 (33\%); squamous cell lung cancer in 7 of $30(23 \%)$; adenocarcinoma 7 of 30 (23\%); and non-small cell lung cancer in 6 of $30(20 \%)$. Four of $30(12 \%)$ were diagnosed as bearers of benign disease: tuberculosis 2 of $4(50 \%)$ and sarcoidosis 2 of 4 (50\%). No complications related to the method were perceived.

Conclusion: This preliminary experience with TBNA in 74 patients indicated that this method is safe, easy to perform with a minimum of complications and useful for the diagnosis and staging of pulmonary neoplasms.

Key words: Bronchoscopy/methods. Carcinoma, bronchogenic/diagnosis. Aspiration/methods. 


\section{INTRODUÇÃO}

A punção aspirativa transbrônquica por agulha (PATA) foi descrita, pela primeira vez, pelo cirurgião argentino Schieppati, em 1949, que conseguiu definir o diagnóstico de carcinoma escamoso puncionando os linfonodos subcarinais de um paciente com tumor do esôfago. Entretanto, somente no início dos anos 80, a PATA começou a ser utilizada através da broncofibroscopia para o diagnóstico e o estadiamento dos linfonodos mediastinais em pacientes portadores de neoplasias pulmonares. A PATA, associada a outros procedimentos endoscópicos, melhora a positividade diagnóstica da broncofibroscopia, mas, apesar disso, ainda é um método pouco utilizado. ${ }^{1,2}$

Dasgupta et $a l^{3}$ utilizaram a punção aspirativa por agulha, através da broncofibrosopia, para o diagnóstico do carcinoma broncogênico que se apresentava como uma lesão endobrônquica exofítica. Os autores notaram que houve um aumento no rendimento diagnóstico nessas lesões quando associaram a PATA aos outros métodos diagnósticos convencionais como a biópsia, o escovado e o lavado brônquicos.

Horsley e et al. ${ }^{4}$ relataram a utilidade da PATA no diagnóstico das lesões submucosas, especialmente aquelas recobertas por mucosa normal, devido à dificuldade de acesso através dos procedimentos endoscópicos habituais.

Shure e Fedullo ${ }^{5}$ utilizaram a PATA para o diagnóstico de doença peribrônquica, na qual existisse infiltração submucosa demonstrável ou compressão extrínseca, e comprovaram sua superioridade quando comparada aos outros métodos.

Estes mesmos autores analisaram também o rendimento da PATA no esclarecimento diagnóstico da linfoadenomegalia mediastinal e subcarinal e conseguiram a mesma efetividade, porém com menor indice de complicações, comparativamente à mediastinoscopia. ${ }^{6}$

A PATA é um procedimento pouco invasivo, seguro, com baixo índice de complicações e que permite a coleta de material tanto para estudo citológico quanto histológico. Este método tem sido utilizado no diagnóstico de massas mediastinais, de lesões submucosas, de nódulos e de massas pulmonares periféricas. Além disso, é de utilidade na avaliação das linfoadenomegalias
Siglas e abreviaturas utilizadas neste trabalho: PATA = Punção aspirativa transbrônquica por agulha $\mathrm{TC}=$ tomografia computadorizada

mediastinais em pacientes portadores de neoplasias pulmonares. ${ }^{1}$

Atualmente, sua utilização mais freqüente está relacionada ao diagnóstico e estadiamento do câncer de pulmão. Nestes casos, ela tem se mostrado útil na redução da morbimortalidade e dos custos relacionados à realização da mediastinoscopia, mediastinotomia ou toracotomia.

Embora vários trabalhos internacionais tenham confirmado a utilidade da PATA, não existe, até o momento, nenhuma publicação nacional referente ao método. 1,3,7

0 presente trabalho relata nossa experiência com a PATA no diagnóstico das lesões pulmonares e mediastinais.

\section{MÉTODO}

Realizamos a avaliação retrospectiva de todas as PATA, realizadas em 74 pacientes consecutivos, em investigação diagnóstica no Serviço de Tórax do Hospital do Câncer - INCA/MS, no Rio de Janeiro (RJ), no período de janeiro de 2000 a junho de 2003. Destes, 49 (66\%) eram homens. A idade dos pacientes variou entre 29 e 80 anos (média de 56 anos e mediana de 59 anos).

Todos os procedimentos foram realizados com a utilização do videobroncofibroscópio Pentax FB 18.

A punção aspirativa foi realizada com a agulha MW-122 (Mill-Rose Laboratories, Mentor, Ohio, EUA), com $13 \mathrm{~mm}$ de comprimento e 22-gauge. Ela é recoberta por bainha de plástico de $140 \mathrm{~cm}$ de comprimento e 1,9 $\mathrm{mm}$ de diâmetro.

Todos os pacientes foram submetidos, previamente, à tomografia computadorizada (TC) do tórax. Os linfonodos maiores do que um centímero, no seu menor diâmetro, identificados pela TC do tórax, foram selecionados para punção. Utilizamos para a localização dos linfonodos o mapa de estações linfonodais da American Thoracic Society (ATS). As estações linfonodais puncionadas foram as mediastinais (4R e 4L e 7) e as hilares (11R e 11L) (Figura 1). 
A PATA foi o primeiro procedimento realizado, antes da inspeção da árvore brônquica, sendo colhidas de três a cinco amostras da estação linfonodal comprometida. 0 aparelho foi introduzido sem o uso da aspiração. Após a coleta do material, realizou-se o esfregaço em lâmina e este foi fixado em álcool a 95\%. Em seguida, a agulha foi lavada com $5 \mathrm{ml}$ de soro fisiológico e os dois materiais foram encaminhados ao laboratório de anatomia patológica para análise citopatológica. Todos os exames foram realizados sem o auxílio da fluoroscopia.

0 material colhido foi classificado como: satisfatório e positivo: material com predomínio de linfócitos e raras células epiteliais, capaz de definir o diagnóstico; satisfatório e negativo: material com predomínio de linfócitos e raras células epiteliais, incapaz de definir o diagnóstico; e insatisfatório: material colhido não representativo de linfonodo.

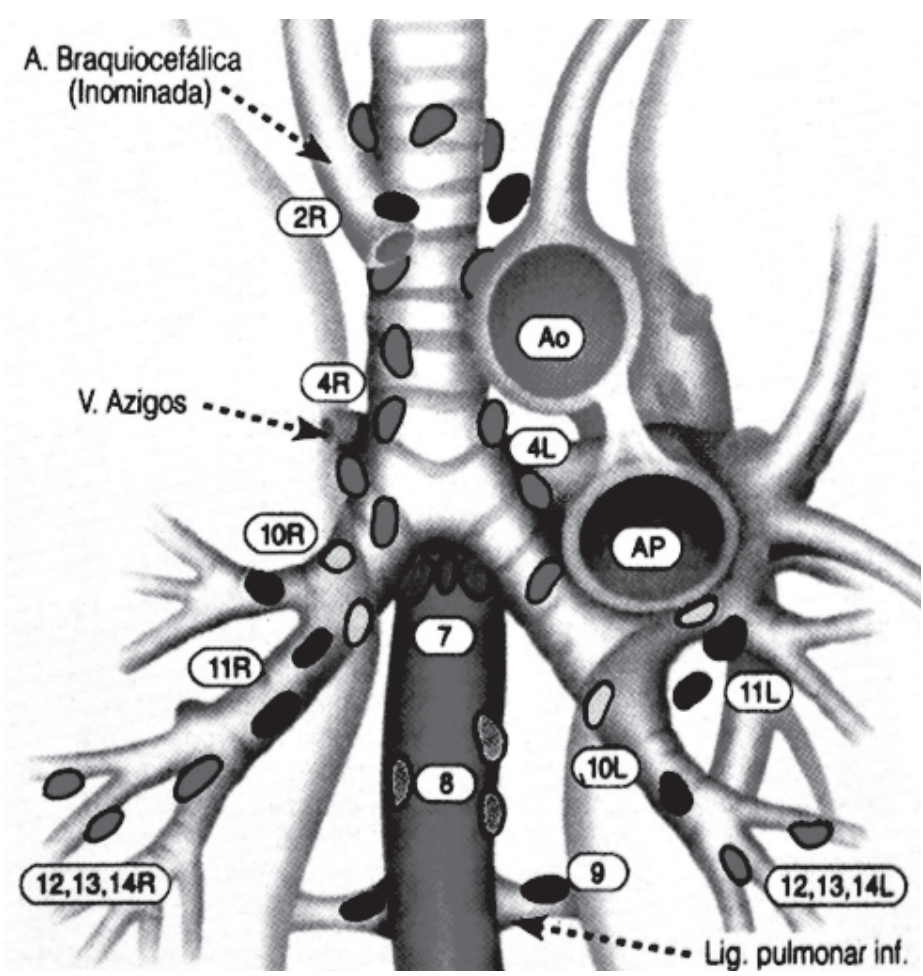

Figura 1. Mapa das estações linfonodais do mediastino segundo a American Thoracic Society
Por se tratar de um método em fase de aprendizado em nosso serviço, todos os pacientes foram posteriormente submetidos à mediastinoscopia e/ou mediastinotomia com biópsia do linfonodo, independentemente da positividade da PATA.

\section{RESULTADOS}

Dos 74 pacientes avaliados, 11 (15\%) apresentavam massa mediastinal (niveis $4 \mathrm{R}, 4 \mathrm{~L}$ e 7) e 63 (85\%) massa hilar (níveis $11 \mathrm{R}$ e $11 \mathrm{~L}$ ) vistas à TC de tórax. Observamos, na árvore traqueobrônquica desses pacientes, 76 alterações endoscópicas: alargamento da carina principal foi o achado mais comum, tendo sido observado em 44 pacientes (59\%); alargamento da carina secundária foi observado em 12 pacientes (16\%); compressão paratraqueal direita ou esquerda, em 5 pacientes (7\%); compressão da parede posterior de traquéia em 3 pacientes (4\%); e compressão do brônquio principal direito ou esquerdo em 5 pacientes (7\%). Dois pacientes apresentaram duas alterações endoscópicas distintas. A broncofibroscopia foi normal em 5 pacientes (7\%) (Figura 2).

Em relação à qualidade do material, observamos que 32 amostras (43\%) não representavam linfonodo, sendo classificadas como insatisfatórias para o diagnóstico. As amostras dos demais 42 pacientes (57\%) foram consideradas satisfatórias. Destas, o material foi considerado satisfatório e diagnóstico em 34 (81\%) e em 8 (19\%) não houve definição de um diagnóstico.

0 rendimento do método, na nossa experiência, foi de 46\% (34/74).

Dos diagnósticos obtidos, 30/34 casos (88\%) representavam doença maligna: carcinoma indiferenciado de pequenas células foi o mais freqüentemente diagnosticado, com 10 casos (33\%); carcinoma escamoso foi diagnosticado em 7 casos (23\%); adenocarcinoma em 7 casos (23\%); e carcinoma não pequenas células em 6 casos (20\%) (Figura 3). Quatro pacientes (4/34) eram portadores de doenças benignas: 2 casos $(50 \%)$ de sarcoidose e 2 casos $(50 \%)$ de tuberculose.

Não houve complicações relacionadas ao método nestes pacientes. 


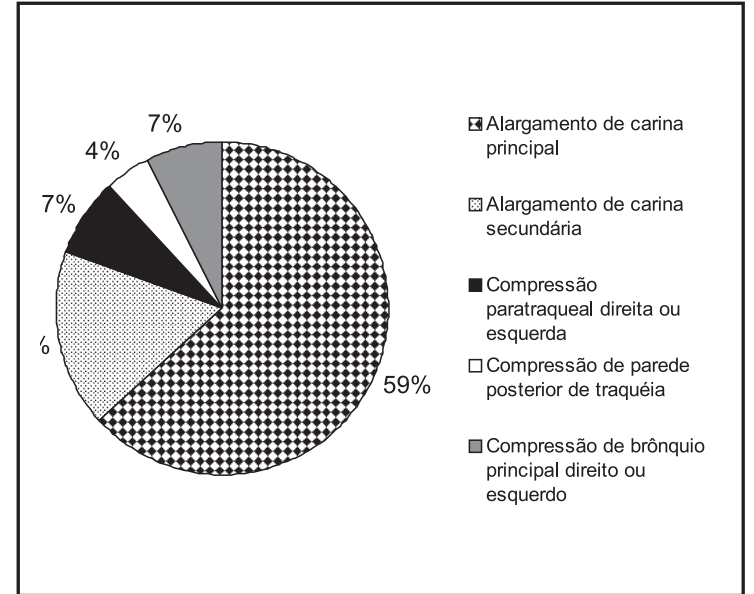

Figura 2. Achados endoscópicos

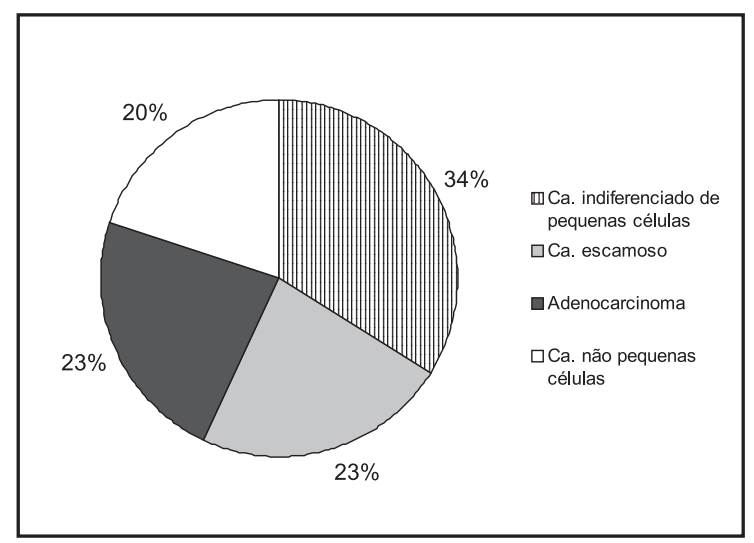

Figura 3. Resultados citológicos nas doenças malignas

\section{DISCUSSÃO}

Apesar do reconhecimento efetivo da utilidade da PATA para o diagnóstico e estadiamento das neoplasias pulmonares, somente um pequeno número de broncoscopistas, em nosso país, realizam a técnica rotineiramente. A pouca utilização do método deve-se à falta de conhecimento a respeito da PATA, à falta de experiência dos examinadores ou simplesmente por se imaginar que as técnicas convencionais sejam suficientes.
Foram submetidos à PATA os pacientes com lesões mediastinais ou hilares, visualizadas à TC de tórax, e a maioria deles apresentava alterações endoscópicas correspondentes aos achados do exame de imagem. A broncofibroscopia normal e a ausência de linfonodos aumentados na TC de tórax não contra-indicam a realização da aspiração com agulha, mas reduzem sua positividade. ${ }^{7}$

Chin et al. ${ }^{8}$ observaram que, quanto maior o menor diâmetro do linfonodo visto à TC de tórax, maior a positividade do procedimento: $44 \%$ nos linfonodos maiores do que $2 \mathrm{~cm}$ e apenas $4 \%$ nos linfonodos menores que $1 \mathrm{~cm}$.

Não observamos diferença de positividade entre as aspirações de linfonodos hilares (45\%) e as de linfonodos mediastinais (55\%), de acordo com o relatado por Harrow et al.(9), que observaram um rendimento de $43 \%$ para linfonodos mediastinais e de $46 \%$ para linfonodos hilares, em um grupo de 360 pacientes avaliados.

Embora possua um valor preditivo positivo que atinge $100 \%$, a PATA apresenta um valor preditivo negativo baixo, necessitando, nos casos de exames negativos, ser complementada com outros testes diagnósticos. Os resultados falso-positivos são raros e podem ser evitados quando as orientações técnicas são seguidas rigorosamente..$^{(1,5,9)}$ Recomenda-se evitar o uso do aspirador até que a PATA tenha sido realizada. Caso haja secreção brônquica, a área a ser puncionada deve ser lavada com solução salina ou lidocaína. A aspiração é realizada após a execução da PATA, antes do exame da árvore traqueo-brônquica. Devemos interromper a sucção da agulha antes de retirá-la do linfonodo, e aspirar, primeiramente, os linfonodos de pior prognóstico. ${ }^{1}$ Esta foi a rotina empregada nos nossos exames.

Não existe consenso a respeito de quantas punções devam ser realizadas em cada estação linfonodal, porém não se observa aumento no rendimento após a sétima aspiração consecutiva. ${ }^{8}$

Dentre os nossos pacientes com diagnóstico de doença maligna, o tipo histológico mais encontrado foi o carcinoma indiferenciado de pequenas células. Este tipo histológico apresenta uma maior positividade diagnóstica quando comparado aos outros tipos de câncer de pulmão. ${ }^{10}$

0 nosso rendimento global foi de $46 \%$, semelhante àquele descrito nas diversas séries da literatura, de $25 \%$ a $80 \% .{ }^{9-11}$ As doenças malignas predominaram 
(30/34 - 88\%) e dentre elas a mais comum foi o carcinoma indiferenciado de pequenas células (10/34 - 33\%). Nossos dados demonstraram que a PATA teve alto rendimento no diagnóstico deste tipo de neoplasia, comparado com as outras neoplasias pulmonares, de outros tipos celulares, o que é consistente com outros relatos publicados., ${ }^{3,7}$ lsto aconteceu, provavelmente, pela alta freqüência na qual o carcinoma indiferenciado de pequenas células produz metástases para os linfonodos mediastinais.

0 rendimento da PATA está diretamente relacionado ao treinamento e à experiência do examinador. ${ }^{12,13}$ As diretrizes do American College of Chest Physicians recomendam um mínimo de 25 exames para capacitar o broncoscopista no procedimento. ${ }^{14}$

A PATA permite acesso a onze estações de linfonodos, porém somente cinco estações são úteis no estadiamento do câncer de pulmão. São elas: estação 7 (linfonodos subcarinais), estação $4 \mathrm{R}$ (direita - linfonodos paratraqueais inferiores direitos), estação 4L (esquerda - janela aortopulmonar) e estações $11 \mathrm{R}$ e $11 \mathrm{~L}$ (direita e esquerda - linfonodos hilares). ${ }^{1}$

0 rendimento diagnóstico da PATA nas lesões neoplásicas endobrônquicas visíveis varia, na literatura, de 65 a 87\%. ${ }^{(1,2,5,6)}$ Embora a biópsia brônquica, nestes casos, tenha um rendimento de $67 \%$ a 100\%, existem algumas situações nas quais a PATA pode ser útil: nas lesões recobertas por tecido necrótico, naquelas lesões com grande possibilidade de sangramento, como nos tumores carcinóides e no carcinoma indiferenciado de pequenas células. ${ }^{(5,6,10)}$

Nas lesões submucosas e peribrônquicas, o rendimento dos procedimentos convencionais, tais como o escovado brônquico e a biópsia brônquica, é baixo. Isto se deve principalmente aos seguintes fatores: as lesões peribrônquicas são inacessíveis à pinça de biópsia por estarem localizadas externamente à via aérea; a infiltração submucosa torna o tecido endurecido e dificulta a biópsia convencional; e a infiltração submucosa pode estar recoberta por tecido normal. Nessas circunstâncias, a adição da PATA aos métodos broncoscópicos tradicionais (escovado, lavado e biópsia brônquicas) aumenta o rendimento diagnóstico. ${ }^{(2,5,6)}$

Shure e Fedullo(5) estudaram 31 pacientes com doença peribrônquica e submucosa. A sensibilidade da biópsia convencional, da PATA, da combinação de ambas e da combinação de todos os métodos diagnósticos foi, respectivamente de 55\%, 71\%, 89\% e $97 \%$.

A PATA com agulha fina tem papel limitado no diagnóstico da sarcoidose, visto que é necessária a identificação do granuloma não caseoso para definição do diagnóstico. Seu uso associado à biópsia transbrônquica e mesmo à biópsia brônquica de mucosa aparentemente normal aumenta a positividade diagnóstica. ${ }^{1}$ Em nosso estudo tivemos o diagnóstico de sarcoidose em 2/34 casos (6\%), com a identificação de granuloma sem necrose caseosa. Este dado, associado à história clínica e aos achados radiológicos, confirma o diagnóstico. Tivemos também 2/34 casos (6\%) de tuberculose com a identificação, no material aspirado, de granuloma de células gigantes (Langhans), tipo corpo estranho e necrose caseosa.

A PATA está contra-indicada naqueles pacientes não cooperantes, com tosse incoercível ou que apresentem distúrbio da coagulação não tratado. A hipertensão arterial pulmonar representa contra-indicação relativa ao método. ${ }^{15}$

As complicações mais graves relacionadas ao método são: pneumotórax, pneumomediastino e hemomediastino. Existe um caso relatado de punção hepática em um paciente com elevação de hemicúpula diafragmática direita. Pequeno sangramento no orifício da punção pode ocorrer, e geralmente é originário de vasos dilatados da parede traqueobrônquica e não da punção de vaso de grande calibre. Febre e bacteremia transitória podem ocorrer após a punção, mas o uso de antibiótico profilático não está estabelecido. 0 problema mais comum associado à PATA é o dano do canal de trabalho do aparelho pela agulha. Para evitá-lo, o broncofibroscópio deve estar retificado durante a progressão da agulha e esta deve estar recolhida dentro de sua bainha., ${ }^{1,2}$

Nossa experiência preliminar indica que a PATA é uma técnica útil e segura. Ela aumenta o rendimento diagnóstico quando associada aos outros métodos da broncoscopia, e quando realizada por examinadores que tiveram treinamento adequado e com experiência. A PATA está recomendada nos pacientes com suspeita de neoplasia pulmonar e com linfoadenomegalia mediastinal. É útil, portanto, no diagnóstico e no tadiamento do câncer do pulmão. 


\section{REFERÊNCIAS}

1. Minai AO, Dasgupta A, Mehta AC. Transbronchial needle aspiration of central and peripheral lesions. In: Bolliger CT, Mathur PN, editors. Interventional bronchoscopy. Basel: Karger; 2000. p.66-79.

2. Dasgupta A, Metha A. Transbronchial needle aspiration an underused diagnostic technique. Clin Chest Med 1999;20:39-51.

3. Dasgupta A, Jain P, Minai AO, Sandur S, Meli Y, Arroliga AC, et al. Utility of transbronchial needle aspiration in the diagnosis on endobronchial lesions. Chest 1999;115:1237-41.

4. Horsley JR, Miller RE, Amy RW, King EG. Bronchial submucosal needle aspiration perfomed through the fiberoptic bronchoscope. Acta Cytol 1984;28:211-7.

5. Shure D, Fedullo PF. Transbronchial needle aspiration in the diagnosis of submucosal and peribronchial bronchogenic carcinoma. Chest 1985;88:49-51.

6. Shure D, Fedullo PF. The role or transcarinal needle aspiration in the staging of bronchogenic carcinoma. Chest 1984;86:693-6.

7. Harrow EM, Abi-Saleh W, Blum J, Harkin T, Gasparini $S$, Addrizzo-Harris DJ, et al. The utility of transbronchial needle aspiration in the staging of bronchogenic carcinoma. Am Rev Crit Care Med $2000 ; 161: 601-7$.
8. Chin R, McCain TW, Lucia MA, Cappellari JO, Adair NE, Lovato JF, et al. Transbronchial needle aspiration in diagnosing and staging lung cancer. how many aspirates are needed? Am J Respir Crit Care Med 2002;166:37781.

9. Harrow EM, Wang KP. The staging of lung cancer by bronchoscopic transbronchial needle aspiration. Chest Surg Clin North Am 1996;6:223-35.

10. Harrow EM, Oldenburg FA, Lingenfelter MS, Smith AM. Transbronchial needle aspiration in clinical practice: a fiveyear experience. Chest 1989;96:1268-72.

11. Fristcher-Ravens A, Soehendra E, Schirrow L, Sriram PVJ, Meyer A, Hauber HP, et al. Role of Transesophageal endosonography-guided fine-needle aspiration in the diagnosis of lung cancer. Chest 2000;117:339-45.

12. Castro FR, López FD, Serdà GJ, López AR, Gilart JF, Navarro PC. Relevance of training in transbronchial fineneedle aspiration technique. Chest 1997;111:103-5.

13. Boyan W, Means-Markwill M. Bronchial needle aspiration learning curve. J Bronchol 2002;9:3-5.

14. Ernst A, Silvestri GA, Johnstone D. Intervenitional pulmonary procedures: guidelines from the American College of Chest Physicians. Chest 2003;123:1693-717.

15. Midthun DE, Cortese DA. Bronchoscopy needle aspiration and biopsy. In: Prakash UBS, editor. Bronchoscopy. 2nd ed. Philadelphia: Lippincott-Raven; 1997. p.147-54. 